\title{
Sampling strategies in forest soils
}

\author{
J Fons ${ }^{*}$, T Sauras $^{2}, \mathrm{~J}$ Romanyà ${ }^{2}$, VR Vallejo ${ }^{2}$ \\ ${ }^{\prime}$ Forest Sciences Department, University of British Columbia, 270-2357 Main Mall, \\ Vancower, BC, Canada V6T IZ4, \\ ${ }^{2}$ Departament de Biologia Vegetal, Facullat de Biologia, Universitat de Barcelona, \\ Avda Diagonal 645, 08028 Barcelona, Spain
}

(Received 31 August 1995: accepted 2 September 1996)

\begin{abstract}
Summary - Many studies have revealed the high variability of soil properties, especially on the forest floor. Sampling techniques have been developed to reduce this variability so as to obtain more precise mean values. Little attention has been paid to the frequency distributions of variables, even though they could provide information on factors that control variability. This paper addresses the selection of the sampling strategy considering the type of study. For the characterization of ecosystems, stratified sampling or systematic sampling is proposed, depending on previous knowledge of the study area. To study processes. two cases were considered: processes that occur within the ecosystem, such as organic matter decomposition, and processes that concern the whole ecosystem, such as fire. In the first case subjective sampling was useful. since it reduced the extrinsic variability of the processes. In the second case, both stratified and systematic sampling were very effective. Frequency distribution analysis was proposed as a tool to detect some factors that control litter accumulation.
\end{abstract}

forest floor / frequency distribution / subjective sampling / stratified sampling / systematic sampling / variability

Résumé - Stratégies d'échantillonnage dans les sols forestiers. Beaucoup d'études ont révélé la grande variabilité des propriétés du sol. en particulier celles relatives aux horizons organiques. Plusieurs techniques d'échantillonnage ont été développées pour réduire la variabilité et obtenir des valeurs moyennes avec précision. Bien que l'étude des distributions de fréquences puisse fournir des informations sur les facteurs qui contrôlent la variabilité. cette approche a reçu peu d'attention. Cet article discute la sélection de stratégies d'échantillonmage selon le type d'étude à effectuer. Pour la caractérisation des écosystèmes on a proposé l'échantillonnage stratifié ou l'échantillonnage systématique. Le choix de l'un ou de l'autre dépend de l'information disponible sur l'aire d'étude. Pour l'étude de processus, deux cas ont été considérés : les processus à l'intérieur de l'écosystème (décomposition de la matière organique) et les processus qui affectent tout l'écosystème (le feu). Dans le premier cas, l'échantillonnage dirigé s'est montré approprié parce qu ii réduit la variabilité extrinsèque

* Correspondence and reprints

Tel: (604) 822 8993: fax: (604) 822 5744: e-mail: fons ( 
au processus. Dans le second cas, les deux techniques d'échantillonnage (stratifié et systématique) ont été efficaces. L'analyse de la distribution des fréquences a été jugée utile pour détecter les facteurs qui contrôlent l'accumulation de la litière.

Distribution des fréquences / échantillonnage dirigé / échantillonnage stratifié / échantillonnage systématique / horizons organiques / variabilité

\section{INTRODUCTION}

Most soil properties are highly variable, especially those of the forest floor (Blyth and Macleod, 1978; Quesnel and Lavkulich, 1980; Arp and Krause, 1984; Carter and Lowe, 1986). According to Allen and Hoekstra (1991), the heterogeneity of natural systems is caused by the interaction of different processes. Some of these processes are often of no interest or not relevant to the aims of the study, obscuring the effects of the factors that are being examined. This is a key issue in ecological research considering that sampling design is still one of the least investigated aspects (Orlóci, 1988). In practice most studies make some assumptions (ie, random samples, normal distribution, etc) that are required for common parametric statistical tests. This practice attempts to take advantage of the fact that the more assumptions that are made, the more informative and reliable conclusions are drawn. However, as noted by Seaman and Jaeger (1990), usual misuses and presumptuous assumptions may weaken the results. Nonparametric statistics avoid these problems and provide a different kind of information related to sample distribution and patterns (Gibbons, 1985; Burke et al, 1988).

Our objective was to establish a guideline for studies on forest soils based on recent reviews on this subject and data from several studies in the Mediterranean region. Specifically we focused on i) setting the basis to determine the appropriate sampling area and sampling size, ii) establishing a rationale for selecting the sampling strategies adequate to the aim of the research, and iii) using nonparametric techniques as a tool to obtain information from variability.

\section{SAMPLING AREA}

Most studies approach the analysis of soil-ecosystem relationships (production, plant composition, etc) using the plot as a sampling unit. It is intended to represent a particular ecosystem or set of environmental conditions. Its area is variable, typically exceeding 0.01 ha (Courtin et al, 1988; Sawyer, 1989). Heterogeneity within the plot reflects the characteristics of the system, but also the author's concept of representativity and homogeneity. Literature on this topic is scant. As an example, Blyth and Macleod (1978) concluded that plots no smaller than 0.5 ha should be used to study soil chemistry.

Another point deserving more attention is the definition of sample volume and sampling depth. Changing any of these may integrate the variability originated from different factors that are relevant at a given scale (Qian and Klinka, 1995). For instance, when studying the litter layer the minimum sample area is derived from the size of the leaves. As surface is increased other factors are integrated and variability fluctuates. Beckett and Webster (1971) considered that $1 \mathrm{~m}^{2}$ may integrate almost all the variability in the plot. Two sample areas, $380 \mathrm{~cm}^{2}$ (Sauras, data not published) and $616 \mathrm{~cm}^{2}$ (Serrasolsas, 1994), were compared to estimate organic matter accumulation in the $\mathrm{H}$ horizon of a holm oak (Quercus ilex $\mathrm{L}$ ) forest (table I). No significant difference was 
Table I. Organic matter accumulation in the $\mathrm{H}$ layer $\left(\mathrm{Mg} \cdot \mathrm{ha}^{-1}\right)$ of a holm oak (Quercus ilex $\mathrm{L}$ ) forest located at Serra de Prades (Tarragona, Spain) from two sample surfaces.

\begin{tabular}{llrrrr}
\hline $\begin{array}{l}\text { Sample } \\
\text { surface } \\
\left(\mathrm{cm}^{2}\right)\end{array}$ & $\mathrm{n}$ & Mean & SD & CV Variance \\
\hline 380.1 & 16 & $38 \mathrm{~ns}$ & 17 & 45 & $284^{* * *}$ \\
615.7 & 16 & $36 \mathrm{~ns}$ & 12 & 33 & $137^{* * *}$
\end{tabular}

$n$ : number of samples; SD: standard deviation; $\mathrm{CV}$ : coefficient of variation; ns: not significantly different: ** $P<0.01$.

observed in the mean but the variance decreased as the sample area increased. This is particularly interesting when working on a plot level as the results suggested that small scale variability can be integrated by increasing sample area.

\section{SAMPLE SIZE}

Assuming the normal distribution, a set of formulas are available to calculate the number of samples needed for a given power of test or error estimation (Zar, 1984). The problem is that, under field conditions, the amount of samples to be collected is usu- ally beyond the possibilities of the study (table II). An alternative criterion could be based on the relationship between sample size and variability, whatever the distribution. In the case of organic matter accumulation on the forest floor, variability stabilized around 16 samples and it was independent from the type of sampling (fig 1). Collecting more samples would increase the power of statistical tests but the

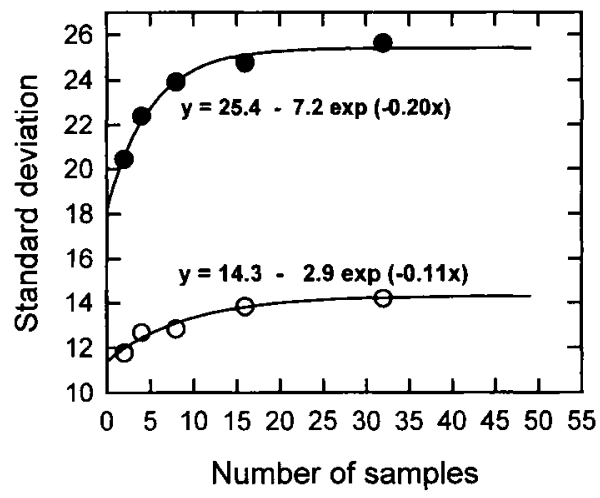

Fig 1. Standard deviation of organic matter accumulation in $\mathrm{H}$ layer related to the number of samples. Solid circles represent a systematic sampling and open circles a subjective sampling from the same holm oak plot in Serra de Prades (Tarragona, Spain).

Table II. Required sample sizes to estimate the true means of organic matter in the forest floor $\left(\mathrm{Mg}^{-1} \mathrm{a}^{-1}\right)$ at $95 \%$ significance level within mean $\pm 5 \%\left(n_{5}\right)$ and mean $\pm 10 \%\left(n_{10}\right)$ range .

\begin{tabular}{lcrrrrr}
\hline Ecosystem & Horizon & $\mathrm{n}$ & $\begin{array}{c}\text { Mean } \\
\left(M_{g} \cdot \mathrm{ha}^{-1}\right)\end{array}$ & $C V$ & $\mathrm{n}_{5}$ & $\mathrm{n}_{10}$ \\
\hline Quercus ilex $^{+}$ & $\mathrm{L}$ & 16 & 3.15 & 48 & 419 & 71 \\
& $\mathrm{~F}$ & 16 & 4.90 & 43 & 336 & 57 \\
Pinus sylvestris $^{++}$ & $\mathrm{H}$ & 16 & 39.17 & 36 & 235 & 40 \\
& $\mathrm{~L}$ & 9 & 3.67 & 20 & 85 & 14 \\
& $\mathrm{~F}$ & 9 & 9.04 & 38 & 307 & 50 \\
& $\mathrm{H}$ & 9 & 40.05 & 28 & 167 & 27 \\
\hline
\end{tabular}

${ }^{*}$ Calculated as $n=t_{\alpha}^{2} S^{2} /(x-\mu)^{2}$, where $t_{\alpha}$ is Student 's $t$ for a particular probability with (n-1) degrees of freedom; $S^{2}$, the estimated variance; $(x-\mu)$ the accepted error; ${ }^{+}$Prades (Tarragona. Spain: Sauras data not published); ${ }^{++}$Montsec (Lleida, Spain; Lauradó et al, 1994), $n$ : number of samples: CV: coefficient of variation. 
variability of the system would already have been integrated within 16 samples.

Composite samples make it possible to decrease the number of samples to be analyzed. The result is a certain decrease in within-site variability and lower precision, but this may not be significant at an ecosystem level (Carter and Lowe, 1986). Composite samples are particularly useful for nutrient studies as soil physical properties usually are more variable and require a greater number of samples than chemical properties (Arp and Krause, 1984).

\section{SAMPLING STRATEGIES}

The objectives of the study are to determine the sampling strategy since the technique used strongly influences the information acquired (Orlóci, 1988). We have considered two groups of studies.

\section{Characterization of ecosystems}

To characterize an ecosystem, its intrinsic variability must be integrated (Orlóci, 1988). It may be accomplished by systematic and stratified sampling. If there is no specific spatial pattern, systematic sampling is recommended because it ensures a better coverage of the population than random samples (Petersen and Calvin, 1986).

Stratified sampling is one of the most precise sampling strategies (Petersen and Calvin, 1986), but it requires previous information on the system for separating the object of study into component parts. Its effectiveness is due to the sampling error arising solely from variations within components and not between them. Then, the effectiveness of the stratified design depends on the relevancy of the criterion adopted for the selection of components in the system. A study on litter accumulation in Pinus halepensis Mill stands (Fons, 1995),
Table III. Litter accumulation $\left(\mathrm{Mg} \cdot \mathrm{ha}^{-1}\right)$ in a Pinus halepensis stand on Massís de Gaià (Catalonia, Spain).

\begin{tabular}{lrrrr}
\hline Plot & Mean & \multicolumn{1}{c}{$\mathrm{S}_{\mathrm{e}}^{2}$} & \multicolumn{1}{c}{$\mathrm{S}_{\mathrm{at}}^{2}$} & $\mathrm{~S}_{\mathrm{e}}^{2} / \mathrm{S}_{\mathrm{a}}^{2}$ \\
\hline 1 & 14.56 & 18.86 & 23.33 & 0.81 \\
2 & 15.83 & 30.60 & 38.86 & 0.79 \\
3 & 20.40 & 117.97 & 139.10 & 0.85 \\
\hline
\end{tabular}

$S_{-2}^{2}$ variance of stratilied sampling; $S^{2}$ : variance of random sampling, estimated from data obtained by stratified sampling using Snedecor and Cochran (1991) transformation.

revealed that error obtained with a stratified sampling based on the litter type within each plot (pine litter and other species litter) was lower than random sampling (table III). Stratified sampling reduced variability by 15 to $20 \%$ and therefore the number of samples can be reduced by an equivalent percentage (Sokal and Rohlf, 1981).

\section{Studying processes}

\section{Processes in the system}

It is desirable to bypass any variability extrinsic to the process and control as much as possible all factors affecting it. Subjective sampling (also called judgement or preferential sampling) allows us to climinate undesirable factors by considering only samples from specific areas of the system (Crepin and Johnson, 1993). Vallejo et al (1990), studying the incorporation and cycling of radionuclides from the Chernobyl accident in lorest ecosystems, selected only samples from under dense canopies and in sites with well-developed forest floors. In a parallel experiment on radionuclide migration in the forest floor, samples were taken $50 \mathrm{~cm}$ from trees either to the right or to the left following the level line (Sauras et al, 1992). A systematic sampling in the same plots (Arias et al, 1991), showed higher variability 
Table IV. Variance of organic matter accumulation in $\mathrm{H}$ horizon $\left(\mathrm{Mg}_{\mathrm{g}} \mathrm{ha}^{-1}\right)$ from two sampling strategies.

\begin{tabular}{lccccc}
\hline Sample strategy & $\mathrm{n}$ & Mean & SD & $C V$ & Variance \\
\hline Subjective & 16 & $36 \mathrm{~ns}$ & 12 & 33 & $137^{* * *}$ \\
615.7 & 16 & $31 \mathrm{~ns}$ & 24 & 78 & $595^{* * *}$
\end{tabular}

n: number of samples; SD: standard deviation; CV: coefficient of variation: ns: not significantly dilferent: $*: P<0.01$.

(table IV). Therefore, the subjective sampling allowed us to limit the variability in the process of interest, and diminished the variability caused by other factors extraneous to this process.

\section{Changes in the whole system}

When studying changes in the whole system, such as fire disturbances, it is necessary to consider all sources of variability in the system. Then, as in characterizing ecosystems, systematic and stratified sampling are the most suitable strategies. When the heterogeneity of the area is readily rec-

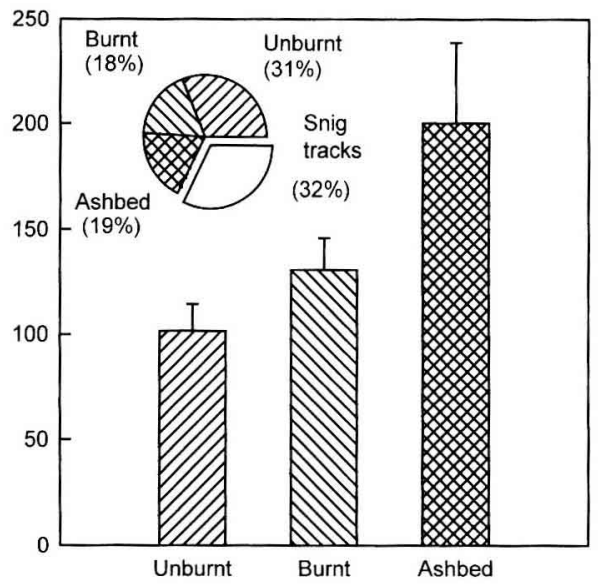

Fig 2. Stratified sampling in a harvested and slash burnt plot. Sampling avoided areas heavily perturbed by logging. Pools of total phosphorus refer to the first $10 \mathrm{~cm}$ of mineral soil. Bars are standard deviation. ognizable a priori, stratified sampling is the most appropriate. For example, Romanyà et al (1994), studying the effects of fire on soil phosphorus availability, surveyed the area prior to sampling using the line-transect method. According to the intensity of fire the site was divided into four strata (fig 2). Areas heavily pertubated by logging operations were avoided, thus the study only included ash bed, burnt and unburnt areas. In each studied stratum systematic sampling was carried out and each stratum was studied separately. Finally, to describe the global effects of fire on soil phosphorus pools, results were integrated considering the magnitude of the effects and the relative surface of each stratum.

\section{ANALYSIS OF VARIABII.ITY}

A study on litter accumulation illustrated the usefulness of frequency distribution analysis detecting some patterns.

The effect of slope position (upper, middle and bottom) and aspect ( $\mathrm{N}$ and $\mathrm{S}$ ) on litter accumulation was studied in Pinus halepe'nsis Mill forests (Fons, 1995). At each combination, two plots were selected ( 16 samples per plot), analysis of variance (ANOVA) revealed only differences between plots, and lack of significance on slope position and aspect was attributed to high variability. The analysis of frequency distributions revealed two different groups (Kolmogorov-Smirnov test): i) top and 


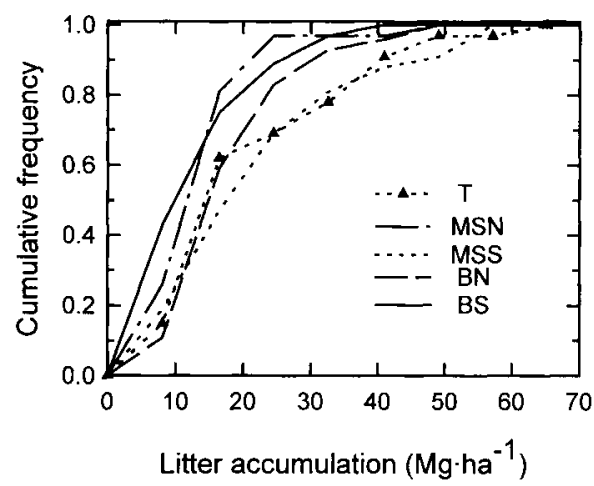

Fig 3. Cumulative frequency distribution of litter accumulation $\left(\mathrm{Mg} \cdot \mathrm{ha}^{-1}\right)$ in Pinus halepensis Mill forests (Massís de Gaià, Catalonia, NE Spain). T: top; MSN: medium slope on $\mathrm{N}$ aspect; MSS: medium slope on the $S$ aspect; BN: bottom on $\mathrm{N}$ aspect; $\mathrm{BS}$ : bottom on $\mathrm{S}$ aspect.

medium $\mathrm{S}$ facing slope, ii) $\mathrm{N}$ aspect and bottom $S$ facing slope (fig 3). Standard deviation, skewness and kurtosis were higher in the first group and data did not fit a normal distribution. However, the data of the second group fitted a normal distribution $(\log N$ for bottom $S$ facing aspect). It can be concluded that the slope position had a significant effect in litter accumulation: heterogeneity was lower on the $\mathrm{N}$ aspect and the maximum differences between distributions were detected between the $\mathrm{N}$ and the $\mathrm{S}$ aspect on the middle slope, decreasing on the bottom. In addition, differences between distributions were caused by differences in higher litter accumulation (points over $20 \mathrm{Mg} \cdot \mathrm{ha}^{-1}$ in fig 3).

\section{CONCLUSIONS}

The study of variability is useful to obtain an optimum experimental design and an optimum allocation of resources in forest soil studies. Minimizing variability may be practical when the aim of the study is to increase precision in measurements and resolution in discriminating between treatments, otherwise variability can be seen as a source of information and used to describe ecosystems. In this case minimizing variability may be a strategy of no interest.

\section{ACKNOWLEDGMENTS}

We thank the Group of Forest Soils (Dep Biologia Vegetal, Universitat de Barcelona) and two anonymous reviewers for helpful comments on the manuscript. This work has been partially supported by the EC Program Environment (EV5VCT 92-(0141).

\section{REFERENCES}

Allen TFH, Hoekstra TW ( 1991$)$ Role of heterogeneity in scaling of ecological systems under analysis. In: Ecological Heterogeneity. Systems Under Analyis. Erological Studies No 86 (J Kolasa, ST Pickett, eds), Springer-Verlag. New York. NY, USA

Arias JJ, Scrtasolsas I, Vallcjo VR, Alcañiz JM, Josa R, Sole A (1991) The Effects of Clearcutting and Fire on the Forest Soils of Prades Mountains (La Conca de Barberii). EC Report EV4V-0109

Arp PA, Krause HH (1984) The forest floor: lateral variability as revealed by systematic sampling. $C a n$ I Soil Sci 64, 423-437

Beckett PTH, Webster R (1971) Soil variability: a revicw. Soils Fertil 34, 1-15

Blyth JP. Macleod DA (1978) The significance of soil variability for forest soil studies in North-East Scotland. J Soil Sci 29, 419-430

Burke PV, Bullen BL, Poff KL (1988) Frequency distribution histograms for the rapid analysis of data Plant Phwiol 87, 797-798

Carter RE, Lowe LE (1986) Lateral variability of forest floor properties under second-growth Douglasfir stands and the usefulness of composite sampling techniques. Can J For Res 16, 1128-1132

Courtin PJ, Klinka K. Feller MC, Demaerschalk JP (1988) An approach to quantitative classification of nutrient regimes of forest soils. Can J Bot 66 , 2640-2653

Crepin J, Johnson RI (1993) Soil sampling for environmental assessment. In: Soil Sampling and Methods of Analysis (MR Carter. ed), Lewis Publishers, Boca Raton, FL, USA, 5-18

Fons J (1995) Avaluació de la Fertilitat en Sòls Forestals Mediterranis. El Cas de les Pinedes de Pi Blane (Pinus halepensis Mill). PhD thesis, Universitat de Barcelona, Barcelona, Spain 
Gibbons JD (1985) Nonparametric Statistical Inference. Marcel Dekker, Inc, New York, NY, USA

Llaurado M, Vidal M, Rauret G, Roca MC. Fons J. Vallejo VR (1994) Radiocaesium behaviour in Mediterranean conditions. J Environ Radioachivity $23,81-100$

Orlóci L (1988) Community organization: reccnt advances in numerical methods. Can J Bot 66 . 2626-2633

Petersen RG, Calvin LD (1986) Sampling. In: Methods of Soil Analysis. I. Physical and Mineralogical Methods (A Klute, ed), Amcrican Society of Agronomy, Soil Science Society of America, Madison, WI, USA, 33-5]

Quesnel HJ, Lavkulich LM (1980) Nutrient variability of forest floor near Port Hardy, British Columbia. Canada. Can J Soil Sci 60, 565-573

Qian H, Klinka K (1995) Spatial variability of humus forms in some coastal forest ecosystems. Ann Sci For 52, 653-666

Romanyà J, Khanna PK, Raison JR (1994) Effects of slashburning on soil phosphorus fractions and sorption and desorption of phosphorus. For Ecol Manage 65.89-103

Sauras T, Roca MC, Vallejo VR, Tent J, Llaurado M, Vidal M, Rauret G (1992) Migration study of radionuclides in Mediterranean forest soils using synthetic aerosols. Seminar on the dynamic behavior of radionuclides in forests. Stockholm, Sweden, May 1992

Sawyer AL (1989) Inconstancy of Taylor's b: simulated sampling with different quadrat sizes and spa tial distributions. Res Popul Ecol 31, 11-24

Seaman JW. Jaeger RG (1990) Statisticae dogmati cate: a critical essay on statistical practice in ecology. Herpetologia 46, 337-346

Serrasolsas I (1994) Ferfilitat dels sols forestals afectats pels foc. Dincimica del nitrogen i el fosfor. PhD thesis, Universitat de Barcelona, Barcelona, Spain

Snedecor GW. Cochran WG (1991) Stafistical Meth ods. Iowa State University Press, Iowa, USA

Sokal RR, Rohlf RJ (1981) Biometry. Freeman, San Francisco, CA, USA

Vallejo VR, Roca MC, Fons J, Rauret G, Llaurado M, Vidal M (1990) Radiocaesium transfer in Mediterranean forest ecosystems. In: Proceedings of the Workshop an "Transfer of Radionaclides in Natural and Semi-Natural Enviromments" ECSC, EEC. EAEC. Elsevier Science Publishers LTD, 103-109

Zar JH (1984) Biostatistical Analwsis. Prentice Hall Inc. Englewood Cliffs, NJ, USA 